\title{
Estado, mercado e formas de privatização: a influência dos think tanks na política educacional brasileira
}

\author{
State, market and forms of privatization: an influence of think tanks on \\ brazilian educational policy
}

\section{Estado, mercado y formas de privatización: Ia influencia de los think tanks en la política educacional brasileña}

\author{
Valdelaine da Rosa Mendes* \\ Vera Maria Vidal Peroni*
}

\section{Resumo}

Há, especialmente no século XXI, uma proliferação dos think tanks que operam como produtores e influenciadores de ideias acerca do mercado, que defendem a redução do intervencionismo estatal nas tomadas de decisões. Este estudo tem como objetivo discutir a influência que têm exercido na organização das políticas educacionais de forma a alargar e intensificar a penetração dos interesses do mercado na área educacional. Para alcançar este propósito, é realizada uma discussão sobre as formas de privatização que têm levado a lógica do mercado para o interior das políticas educacionais. É traçado um panorama da distribuição dessas organizações no mundo, com as características de seus financiadores e apoiadores. Por fim, são apresentados os princípios que orientam as ações de três think tanks: um estadunidense e dois brasileiros, com foco nas questões educacionais. Este estudo demonstrou que os interesses do capital, representados por organizações financiadas por grandes empresas (com capacidade de penetração na imprensa, nos governos, nas universidades, nas mídias sociais, na indústria cultural), pretendem claramente determinar ao Estado uma perspectiva privada na definição e na concepção das políticas educacionais.

Palavras-chave: Política educacional. Think tank. Privatização. Mercado.

Recebido em 13/04/2019 - Aprovado em 29/08/2019

http://dx.doi.org/10.5335/rep.v27i1.10575

Doutora em Educação pela Universidade de São Paulo (USP, Brasil), com estágio pós-doutoral em Educação pela Universidade de São Paulo. É professora associada da Faculdade de Educação da Universidade Federal de Pelotas (UFPel, Brasil). ORCID http://orcid.org/0000-0003-4376-1080. Pós-doutoranda no Programa de Pós-graduação em Educação da Universidade Federal do Rio Grande do Sul. E-mail: valdelainemendes@outlook.com

** Doutora em Educação pela Pontifícia Universidade Católica de São Paulo (PUC SP, Brasil), com estágio pós-doutoral pela Universidade do Minho (Uminho, Portugal). Professora convidada do Programa de Pós-graduação em Educação da Universidade Federal do Rio Grande do Sul (Ufrgs, Brasil) e professora visitante na Universidade Federal de Pelotas (UFPel, Brasil). ORCID http://orcid.org/0000-0001-6543-8431. E-mail: veraperoni@gmail.com 


\section{Abstract}

There is, especially in the 21st century, a proliferation of think tanks that operate as producers and influencers of market ideas, advocating the reduction of state interventionism in decision making. This study aims to discuss the influence they have exerted on educational policies in order to broaden and intensify the penetration of market interests in the educational area. To achieve this purpose, a discussion is held on the forms of privatization that have brought the logic of the market into educational policies. An overview is given of the distribution of organizations in the world, with characteristics of their funders and supporters. Finally, the principles that guide the actions of two think tanks are presented, one American and two Brazilian, which focus on educational issues. This study has shown that the interests of capital, represented by organizations funded by large corporations (which are able to gain entrance into the press, governments, universities, social media and the cultural industry) are intended to clearly determine the State a private perspective in the definition and design of educational policies.

Keywords: Educational policy. Think tank. Privatization. Market.

\section{Resumen}

Existe, especialmente en el siglo XXI, una proliferación de think tanks que operan como productores e influenciadores de ideas acerca del mercado, que defienden la reducción del intervencionismo estatal en la tomada de decisiones. Este estudio tiene como objetivo discutir la influencia que han ejercido en la organización de las políticas educacionales de forma a estrechar e intensificar la penetración de los intereses del mercado en el área educacional. Para alcanzar este propósito realizamos una discusión acerca de las formas de privatización que han permeado la lógica del mercado en el interior de las políticas educacionales; se ha trazado un panorama de la distribución de esas organizaciones en el mundo, con las características de sus financiadores y apoyadores. Por fin, son presentados los principios que orientan las acciones de dos think tanks: un estadunidense y dos brasileños, con foco en las cuestiones educacionales. Este estudio ha demostrado que los intereses del capital, representados por organizaciones financiadas por grandes empresas (con capacidad de penetración en la prensa, en los gobiernos, en las universidades, en los medios de comunicación social y en la industria cultural), pretenden claramente determinar al Estado una perspectiva privada en la definición y concepción de las políticas educacionales.

Palabras-clave: Política educacional. Think tank. Privatización. Mercado.

\section{Introdução}

Os think tanks são organizações que existem desde o século XIX e atuam como formuladoras de ideias e opiniões, produtoras de conhecimento e influenciadoras de políticas públicas nas mais diversas áreas de atuação. Essas organizações estão presentes em diferentes partes do planeta e operam muito próximas das instâncias governamentais. Trata-se de um tipo de atuação capaz de dar o direcionamento para os fundamentos das ações tanto no legislativo quanto no executivo.

Na segunda década do século XXI, há um crescimento significativo do número de think tanks no mundo e, mais especificamente na América Latina, em áreas como saúde, defesa, meio ambiente, educação, política externa, libertarianismo, 
entre outras. Essas organizações agem de forma articulada com outros grupos de interesse e, mesmo com registro em uma nação, criam ramificações em diferentes países, para exercer influência na formação de políticas e de opinião pública.

O Brasil assiste, em especial na segunda década do século XXI, o crescimento dos think tanks pró-mercado, que podem operar eminentemente com as questões econômicas, ou ter uma atuação ampliada para outras esferas da vida social como meio ambiente, saúde, educação, violência, segurança pública, entre outras, atreladas aos valores gerencialistas do mercado.

Ainda são poucos os estudos no país que se debruçam sobre a interpretação do papel que essas organizações têm na educação brasileira. Observamos, tanto dentro quanto fora do meio acadêmico, a urgência de aprofundamento sobre a amplitude, o tamanho e a capilaridade dessas organizações.

Este estudo tem como objetivo discutir a influência que os think tanks têm exercido na organização das políticas educacionais, de forma a alargar e intensificar a penetração dos interesses do mercado na área educacional. Neste artigo, em um primeiro momento, é realizada uma discussão sobre as formas de privatização que têm levado a lógica do mercado para o interior das políticas educacionais, como reflexo de uma disputa por um projeto societário. Para entender o papel que desempenham os think tanks, neste momento de desenvolvimento do capitalismo, e sua influência nas políticas externas e internas dos países, logo em seguida, é traçado um panorama da distribuição dessas organizações no mundo, com as características de seus financiadores e apoiadores. Depois de construída essa fundamentação, são apresentados os princípios que orientam as ações de think tanks, um estadunidense e dois brasileiros, com foco nas questões educacionais.

\section{Estado, mercado e formas de privatização}

Este texto tem como base pesquisas acerca da relação entre o público e o privado na educação, entendida como parte de um processo de correlação de forças que ocorre na sociedade. Partindo do conceito de políticas sociais como parte da materialização do Estado, em um período particular do capitalismo, buscamos entender como se efetiva a relação entre o público e o privado na educação, por meio de sujeitos que defendem projetos societários distintos. Assim, o foco deste artigo é mostrar como atuam dois sujeitos, via think tanks, vinculados ao mercado e qual o conteúdo de suas propostas para a educação. 
Os processos de privatização do público podem ocorrer via execução e direção, em que o privado opera diretamente na oferta da educação, ou quando a atuação do privado ocorre na direção das políticas públicas ou das escolas, sendo que a propriedade permanece pública (PERONI, 2016). Nesse sentido, reiteramos que na nossa concepção, a relação público-privada não está vinculada apenas à propriedade, mas à projetos societários em disputa em uma perspectiva de classe. Classe aqui entendida como "uma relação e não uma coisa" (THOMPSON, 1981, p. 11), sendo que “[...] não é esta ou aquela parte da máquina, mas a maneira pela qual a máquina trabalha" (THOMPSON, 2012, p. 169).

Assim, os processos de privatização do público, materializam-se principalmente através da disputa pelo conteúdo da educação, assim como, pelo fundo público. Rikowski (2017) ressalta que existem duas formas básicas de privatização: a privatização direta, que se refere à propriedade e trata da conversão da receita do Estado em lucro privado; e a privatização da educação, que se refere a formas de controle sobre a educação por parte das empresas. É importante distinguir a natureza da privatização, pois pode trazer diferentes consequências para a educação.

A privatização na educação envolve o controle das escolas e ocorre quando não há mudança de propriedade, mas o privado assume o conteúdo da educação com pautas como o individualismo, a competição, a meritocracia. Envolve o que Rikowski (2017) chama de capitalização da educação, que ocorre quando o privado transforma a receita estatal em lucro:

[...] a privatização da educação não é realmente sobre educação: trata-se de se beneficiar da receita do Estado e transformá-la em lucro. [...] A política de privatização educacional (ou de qualquer outra forma) é a obtenção de lucros, que por sua vez se baseia na capitalização de instituições e serviços educacionais; educação tornando-se capital. Trata-se do desenvolvimento capitalista na educação (2017, p. 401).

Esta pauta é parte do diagnóstico neoliberal, pactuado pela terceira via (atual social- democracia), de que o Estado é o culpado pela crise e o mercado deve ser o padrão de qualidade. Nessa perspectiva, a responsabilidade pela execução e direção das políticas sociais deve ser repassada para a sociedade civil com ou sem fins lucrativos.

A terceira via, desloca das bases teóricas históricas da social-democracia, a questão da igualdade social para a meritocracia, passando de uma proposta coletivista para uma individualista vinculada ao mercado, sem evidenciar a profundidade dessa mudança e suas consequências para a efetivação dos direitos sociais (PERONI, 2013). Para Giddens (2007, p. 253), “os social-democratas precisam revisar 
não apenas sua abordagem, mas também seu conceito de igualitarismo [...] não há futuro para o igualitarismo a todo custo, que absorveu por tanto tempo os esquerdistas". Nesse sentido, a terceira via defende o empreendedorismo como elemento estruturante da sociedade para o enfretamento dos problemas sociais.

O empreendedorismo civil é qualidade de uma sociedade civil modernizada. Ele é necessário para que os grupos cívicos produzam estratégias criativas e enérgicas para ajudar na lida com problemas sociais. O governo pode oferecer apoio financeiro ou proporcionar outros recursos a tais iniciativas (GIDDENS, 2007, p. 26).

A terceira via defende que a social-democracia deve passar dos princípios de direitos sociais universais para uma concepção individualista. O objetivo geral "deveria ser ajudar os cidadãos a abrir seu caminho através das mais importantes revoluções do nosso tempo: globalização, transformações na vida pessoal e nosso relacionamento com a natureza" (GIDDENS, 2001b, p. 74). Assim, cada um é responsável por, individualmente, abrir o seu caminho de modo que as transformações aconteçam na esfera pessoal e não societária. Essa concepção exacerba o que sempre foi um princípio do capitalismo, o individualismo.

Harvey (2008), ao tratar da neoliberalização, que é o balanço da teoria neoliberal na prática, destaca que o mercado regula o bem-estar humano e a competição é o mecanismo regulador. Assim, o sucesso e o fracasso são considerados individuais, resultado das virtudes empreendedoras do indivíduo. Para essa teoria, as classes inferiores pioraram por razões pessoais e culturais, na tarefa de aprimorar o capital humano e, consequentemente, a dedicação à educação. Tudo pode ser tratado como mercadoria. A mercadificação presume a existência de direitos de propriedade sobre processos, coisas e relações sociais. É o que o autor chama de "mercadificação de tudo".

Para Harvey (2008), as questões das liberdades individuais, no contexto atual, trouxeram perdas para um projeto societário baseado na coletividade, justiça social e democracia:

[...] os valores 'liberdade individual' e 'justiça social' não são necessariamente compatíveis. A busca da justiça social pressupõe solidariedades sociais e a propensão a submeter vontades, necessidades e desejos à causa de uma luta mais geral em favor de, por exemplo, igualdade social ou justiça ambiental (HARVEY, 2008, p. 51).

Verificamos, assim, que o individualismo é uma posição comum ao neoliberalismo e à terceira via. De alguma forma, as duas teorias propõem o repasse para a sociedade, em alguma medida, da direção e da execução das políticas sociais. 
Atualmente, além do privado vinculado ao mercado também vivenciamos o neoconservadorismo. Conforme Moll Neto (2010, p. 65), a "ideologia neoconservadora resgatou e reconstruiu pressupostos de correntes conservadoras que os antecederam, basicamente do velho conservadorismo e do libertarianismo". Conforme o autor, os intelectuais que construíram as bases ideológicas do neoconservadorismo resgataram do tradicionalismo a ênfase moral que, a partir da década de 1960, serviu para atacar o Estado de Bem-Estar Social e os movimentos sociais liberais; e do libertarianismo, a ideia de que a sociedade era uma relação contratual entre indivíduos e não um organismo que guarda interesses e objetivos coletivos. Para eles, "[...] nada justificava projetos estatais que interferissem na vida das pessoas e limitassem as liberdades, sobretudo a econômica" (MOLL NETO, 2010, p. 67). A partir da crise da década de 1970, inicia-se uma mobilização neoconservadora por meio da criação de think tanks em que "os empresários da nova direita organizaram fundações para reunir capital para apoiar e financiar universidades, pesquisas e centros de estudo (think tanks) a fim de elaborar projetos políticos nacionais" (MOLL NETO, 2010, p. 69).

Destacamos, assim, que a retirada de direitos sociais e trabalhistas, com a lógica de mercado na esfera pública, bem como o avanço do neoconservadorismo não foi simplesmente aceito pela população, foi um longo trabalho de sujeitos individuais e coletivos, organizados ou não em redes nacionais e internacionais. A seguir, traremos o papel dos think tanks nesse processo de convencimento.

Rocha (2015, p. 262), define think tanks: “[...] como instituições permanentes de pesquisa e análise de políticas públicas que atuam a partir da sociedade civil, procurando informar e influenciar tanto instâncias governamentais como a opinião pública no que tange à adoção de determinadas políticas públicas”. Desde o início da sua atuação, a pretensa excelência dos think tanks pró-mercado estava em pertencer à sociedade civil, no sentido de não serem públicos, de serem apolíticos e isentos, partindo do ideário neoliberal de que a crise é do Estado, sendo o mercado o parâmetro de qualidade, como já apresentamos neste texto.

[...] estas organizações não sofreriam interferência ou pressão de grupos de interesse específicos, como ocorreria em agências estatais, governos, universidades ou partidos, o que lhes facultaria a possibilidade de conduzir suas atividades-fim de forma mais 'neutra', 'científica' e 'desinteressada', e por isso mais 'confiável' em comparação a outros locais de pesquisa e produção de ideias e políticas públicas [...] (ROCHA, 2017, p. 97).

Apesar de se colocarem como neutros e apolíticos, os think tanks têm clara perspectiva de classe. Moraes (2016) ressalta que os milionários americanos disseminaram a cultura de mercado, entre outros fatores, como parte do esforço de mu- 
dar a imagem do empresariado perante a opinião pública e influenciar o ambiente político, por meio dos think tanks:

[...] a 'novíssima direita' cria e multiplica think tanks e aparatos de mídia (impressa, eletrônica, virtual etc.) para modelar o ambiente político. De outro lado, operando também como lobbies (pressionando para aprovação de certas políticas ou para o direcionamento das já existentes), eles conseguem esse mesmo objetivo: policies make polity, diz a sentença. Assim, por exemplo, ocorre com o fato de determinados programas públicos (provisão de saúde, educação etc.) serem financiados pelo público, mas 'entregues' através de canais privados: isto os faz, ainda que públicos, reconhecíveis pelo usuário como privados (2016, p. 240).

A seguir, abordaremos como atuam os think tanks, quem são, como estão distribuídos internacionalmente, quem são seus apoiadores e financiadores.

\section{A distribuição dos think tanks no mundo}

A Universidade da Pensilvânia, localizada nos Estados Unidos da América (EUA), elabora anualmente um relatório dos think tanks mais influentes no mundo. Esses relatórios são produzidos desde o ano de 2007 e estão disponíveis para consulta no site da universidade. Os critérios definidos pela instituição para avaliar cada think tank são: comprometimento e liderança de suas equipes; reputação acadêmica; número, qualidade e alcance das publicações; presença nas redes sociais; habilidade de recrutar e manter analistas de renome e desenvolver parcerias com outras organizações, entre outros.

Os think tanks têm como propósito exercer influência tanto na política interna dos países onde estão sediados, quanto nas políticas externas. Para tanto, criam redes de relações e propagam-se por diversas nações. No ano de 2018, a Europa era a região do planeta que concentrava o maior número de think tanks, acompanhada da América do Norte, conforme pode ser visto na tabela a seguir:

Tabela 1 - Distribuição de think tanks no mundo em 2018

\begin{tabular}{l|c}
\hline \multicolumn{1}{c|}{ Região } & Quantidade \\
\hline América do Norte & 2.058 \\
América do Sul e Central & 1.023 \\
África Subsaariana & 612 \\
Europa & 2.219 \\
Leste e Norte da África & 507 \\
Ásia & 1.829 \\
TOTAL & 8.248 \\
\hline
\end{tabular}

Fonte: University of Pensylvania Scholarly Commons. Global Go To Think Tank Index Reports, 2018. 
Essa é uma distribuição que mostra a presença de número significativo de think tanks em todas as partes do mundo, entretanto, uma análise direcionada para cada região revela que alguns países concentram a existência dessas organizações. De um total de 8.248, em 2018, um único país, os EUA, sediava 1.871 think tanks, o que representa quase um quarto da totalidade dessas organizações. A tabela a seguir mostra os 25 países com maior número de think tanks nos anos de 2008,2017 e 2018.

Tabela 2 - Os 25 países com o maior número de think tanks, 2008, 2017, 2018

\begin{tabular}{|c|c|c|c|c|c|c|}
\hline \multirow{2}{*}{ País } & \multicolumn{2}{|c|}{2008} & \multicolumn{2}{|c|}{2017} & \multicolumn{2}{|c|}{2018} \\
\hline & Quantidade & Colocação & Quantidade & Colocação & Quantidade & Colocação \\
\hline Estados Unidos & 1.777 & $1^{\circ}$ & 1.872 & $1^{\circ}$ & 1.871 & $1^{\circ}$ \\
\hline Reino Unido & 283 & $2^{\circ}$ & 444 & $3^{\circ}$ & 321 & $4^{\circ}$ \\
\hline Alemanha & 186 & $3^{\circ}$ & 225 & $5^{\circ}$ & 218 & $6^{\circ}$ \\
\hline França & 165 & $4^{\circ}$ & 197 & $6^{\circ}$ & 203 & $8^{\circ}$ \\
\hline Argentina & 122 & $5^{\circ}$ & 146 & $7^{\circ}$ & 227 & $5^{\circ}$ \\
\hline Índia & 121 & $6^{\circ}$ & 293 & $4^{\circ}$ & 509 & $2^{\circ}$ \\
\hline Rússia & 107 & $7^{\circ}$ & 103 & 9o & 215 & $7^{\circ}$ \\
\hline Japão & 105 & $8^{\circ}$ & 116 & $8^{\circ}$ & 128 & $9^{\circ}$ \\
\hline Canadá & 94 & $9^{\circ}$ & 100 & $10^{\circ}$ & 100 & $12^{\circ}$ \\
\hline Itália & 87 & $10^{\circ}$ & 100 & $10^{\circ}$ & 114 & $10^{\circ}$ \\
\hline África do Sul & 78 & $11^{\circ}$ & 92 & $12^{\circ}$ & 92 & $13^{\circ}$ \\
\hline China & 74 & $12^{\circ}$ & 512 & $2^{\circ}$ & 507 & $3^{\circ}$ \\
\hline Suíça & 72 & $13^{\circ}$ & 76 & $14^{\circ}$ & 78 & $17^{\circ}$ \\
\hline Suécia & 68 & $14^{\circ}$ & 89 & $13^{\circ}$ & 90 & $14^{\circ}$ \\
\hline Holanda & 55 & $15^{\circ}$ & 76 & $14^{\circ}$ & 83 & $16^{\circ}$ \\
\hline México & 54 & $16^{\circ}$ & 74 & $16^{\circ}$ & 86 & $15^{\circ}$ \\
\hline România & 53 & $17^{\circ}$ & & & & \\
\hline Espanha & 49 & $18^{\circ}$ & 63 & $21^{\circ}$ & 66 & $22^{\circ}$ \\
\hline Bélgica & 49 & $19^{\circ}$ & 61 & $23^{\circ}$ & & \\
\hline Israel & 48 & $20^{\circ}$ & 67 & $18^{\circ}$ & 69 & $19^{\circ}$ \\
\hline Ucrânia & 45 & $21^{\circ}$ & & & & \\
\hline Hungria & 40 & $22^{\circ}$ & & & & \\
\hline Polônia & 40 & $23^{\circ}$ & 60 & $24^{\circ}$ & & \\
\hline Brasil & 39 & $24^{\circ}$ & 93 & $11^{\circ}$ & 103 & $11^{\circ}$ \\
\hline Nigéria & 38 & $25^{\circ}$ & & & & \\
\hline Áustria & & & 68 & $17^{\circ} \stackrel{\circ}{0}$ & 74 & $18^{\circ}$ \\
\hline Olívia & & & 66 & $19^{\circ}$ & 66 & $20^{\circ}$ \\
\hline Chile & & & 63 & $21^{\circ}$ & 64 & $22^{\circ}$ \\
\hline Colômbia & & & & & 64 & $22^{\circ}$ \\
\hline Irã & & & 64 & 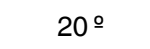 & 64 & $22^{\circ}$ \\
\hline Taiwan & & & 58 & $25^{\circ}$ & 61 & $25^{\circ}$ \\
\hline
\end{tabular}

Fonte: University os Pesylvania Scholarly Commons. Global Go To Think Tank Index Reports, 2008, 2017 e 2018. 
Na Tabela 2, é possível observar que os cinco países com maior número de think tanks somam quase $44 \%$ do total existente no mundo. Os EUA, o primeiro colocado, não muda de posição e tem um crescimento dessas organizações de aproximadamente 5\% de 2008 para 2018, diferentemente do que ocorre com Índia, China e Brasil que têm um crescimento expressivo e mudam de posição na classificação

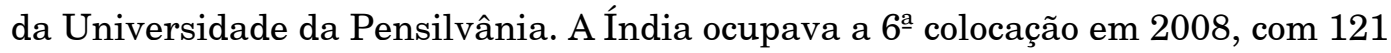
think tanks, e passa a ocupar a $2^{\mathrm{a}}$ posição em 2018, com 509, o que significa um aumento de $322 \%$. A China ocupava a $12^{\mathrm{a}}$ colocação em 2008 , com 74 think tanks, e passa a ocupar a $3^{\mathrm{a}}$ em 2018, com 507, o que representa uma expansão de $585 \%$.

Além dos três países que se encontram nas primeiras colocações vale aqui observar a posição da Argentina e do Brasil. A Argentina ocupava a $5^{\mathbf{a}}$ colocação em 2008, com 122 think tanks, e conserva a mesma posição em 2018, mas com 227 organizações e um crescimento de $86 \%$. O Brasil, que particularmente interessa a este estudo, ocupava em 2008 a $24^{a}$ colocação e passa a ocupar a $11^{\mathrm{a}}$ em 2018 , com um aumento de $165 \%$ no número de think tanks. Apenas três países da América Latina aparecem entre os 25 primeiros colocados na classificação quantitativa do Relatório da Pensilvânia. Além de Argentina e Brasil, o Chile figura em $22^{\circ}$ lugar, com 64 think tanks, no Relatório de 2018.

O quantitativo de organizações internas pode não representar exatamente a força de influência dos think tanks nas políticas locais, já que o relatório analisa a organização com base na informação de localização de sua sede e não na atuação internacional. Muitas dessas organizações possuem sede em um país, mas operam em dezenas de outras nações, exercendo grande influência na política interna dos países.

$\mathrm{Na}$ tabela 2, é possível perceber que justamente os países que compõem o G20 ${ }^{1}$, em sua maioria, figuram entre aqueles com maior número de think tanks. As duas maiores economias do mundo EUA e China ocupam as primeiras colocações no ranking. Há, indubitavelmente, uma correlação entre think tanks e a conservação do modo de produção capitalista. Prevalece na atuação dos think tanks pró-mercado (conservadores e libertários) a lógica da defesa da liberdade econômica, sendo os libertários mais avessos a qualquer intervenção do Estado na promoção de políticas sociais (TEIXEIRA, 2007). Há produção e difusão de conhecimentos para alavancar políticas públicas alicerçadas nos princípios da liberdade individual, em detrimento da organização de políticas que promovam a redução da concentração de riqueza. É o que Harvey (2008) chama de projetos incompatíveis com a justiça social. 
Essas organizações atuam nas mais variadas áreas para influenciar econômica, social e culturalmente os povos, tanto na elaboração de políticas, quanto na formação da opinião pública, para fazer valer os interesses dos grupos que representam e dos que financiam essas instituições, aspecto que revela o perfil do think tank. Eles realizam pesquisas, produzem materiais, sistematizam dados, concedem entrevistas em canais de TV e escrevem artigos para jornais, como forma de inculcar, em parcela significativa da sociedade, suas formas de interpretação da realidade.

Para Ravitch (2011), em gerações de acadêmicos e jornalistas foram incubadas ideias pró-mercado por essas organizações. A autora faz uma análise da realidade estadunidense e mostra que a defesa dos interesses do capital não ficará restrita ao período de um governo, pois ao serem assimiladas por gerações, serão defendidas por indivíduos ou grupos, mesmo ao término dos mandatos.

A seguir, apresentaremos a relação de um think tank internacional, Instituto Brookings com um think tank brasileiro, Fundação Getúlio Vargas (FGV). Escolhemos este exemplo, pois, o Instituto Brookings é o think tank mais bem avaliado no Relatório da Universidade Pensilvânia, por vários anos, e tido como o mais influente no mundo e, a FGV, por ser o think tank mais influente na América do Sul e Central, no mesmo Relatório, e por abrigar o Centro de Excelência e Inovação em Políticas Educacionais (Ceipe), primeiro think tank especializado em política educacional no Brasil.

\section{Instituto Brookings e Fundação Getúlio Vargas: parceiros no Brasil}

O Instituto Brookings, sediado em Washington, foi fundado em 1916 e, de acordo com Teixeira (2007, p. 123), nas últimas décadas, concentrou esforços "para desenvolver novas abordagens para saúde, políticas fiscais, educação, bem-estar social, serviço público, financiamento de campanhas eleitorais e o novo ambiente de segurança internacional resultante do fim da Guerra Fria e da integração global". A autora ainda lembra que, após o 11 de setembro de 2001, passaram a ganhar maior atenção da organização temas como: terrorismo, democracia, segurança $\mathrm{x}$ liberdade individual, assim como questões de governança e liderança.

O Instituto Brookings "é uma organização sem fins lucrativos dedicada a pesquisas independentes e aprofundadas que levam idéias pragmáticas e inovadoras sobre como resolver problemas enfrentados pela sociedade" (BROOKINGS INSTITUTE, 2018, não paginado). É uma organização que se define como independente e neutra em relação às questões que analisa. 
Essa é uma característica que pode ser observada nos thinks tanks pró-mercado, como se a interpretação dos dados de pesquisa pudesse estar desconectada dos pressupostos epistemológicos que fundamentam os processos investigativos (GAMBOA, 2012); como se a própria escolha de um tema ou foco para análise não estivesse carregada de intenções e interesses e pudesse ser considerada independente e neutra. A pretensa neutralidade das organizações pode ser analisada a partir da composição dos seus financiamentos, conforme observamos no gráfico 1 , que apresenta dados do Instituto Brookings:

Gráfico 1 - Composição do orçamento do Instituto Brookings

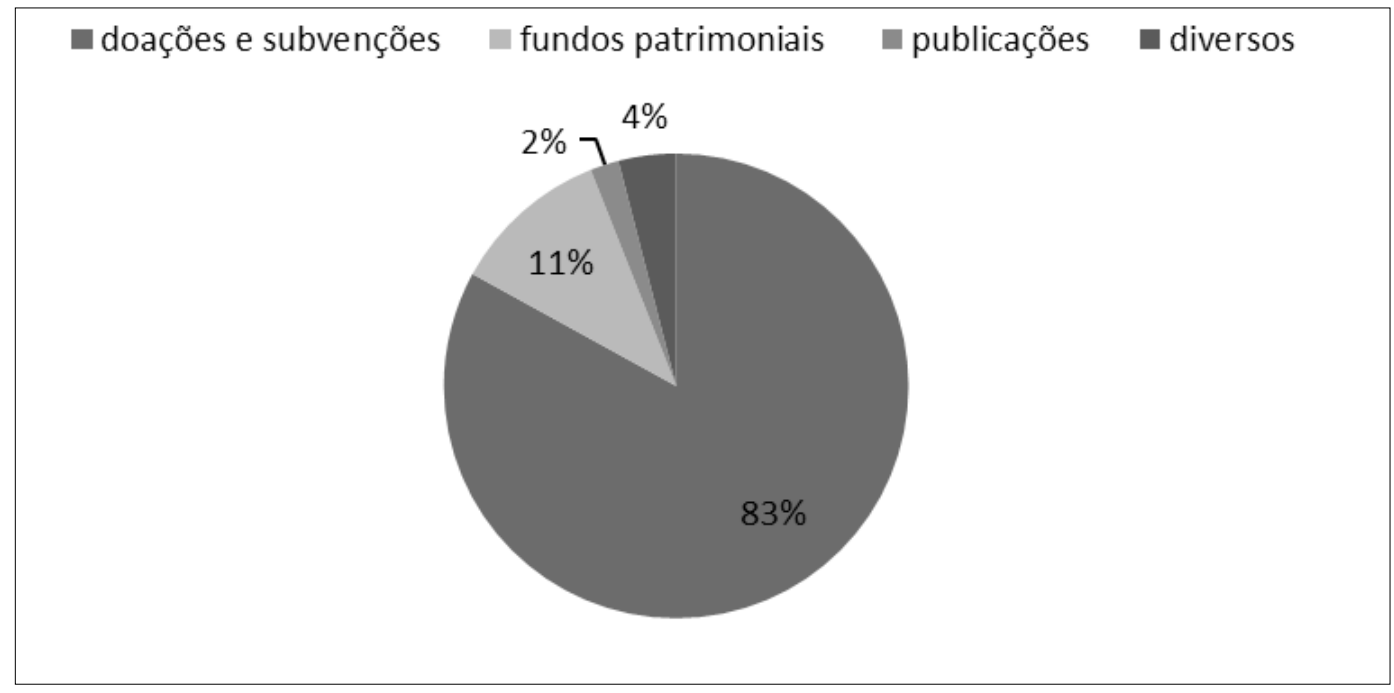

Fonte: Brookings, quality, Independence, impact, 2018, annual report.

Destacamos que a composição orçamentária de um think tank é muito importante para entender os interesses que determinam e definem as ações a serem executadas, o que coloca "em xeque" a independência dessas organizações. As fundações privadas exercem, nos EUA, uma influência importante nas reformas educacionais, já desde a segunda metade do século XX. Se, por longo tempo, os investimentos privados, oriundos de doações e subvenções, não representavam uma ameaça porque eram destinados às instituições educacionais, que decidiam autonomamente como alocar esses recursos, isso se modifica, a partir dos anos 1990, quando as reformas educacionais naquele país passam a sofrer a influência direta dos "filantropos", que usam seus recursos para promover seus objetivos na área educacional e "defender estratégias de reforma que espelhavam sua própria experiência em adquirir grandes 
fortunas, como a competição, a escolha escolar, a desregulamentação, os incentivos e outras abordagens de livre-mercado" (RAVITCH, 2011, p. 224).

As prioridades educacionais são antagônicas às prioridades do mercado, porém "a oferta de uma doação multimilionária por uma fundação é o bastante para fazer com que a maior parte dos superintendentes e conselhos escolares largue tudo e reorganize suas prioridades" (RAVITCH, 2011, p. 224).

O grande perigo da presença dessas instituições nos sistemas educacionais é que elas não são organizações públicas, a sua intervenção nas escolas e redes não está sujeita ao controle público do cidadão. Sobre esta questão, Ravitch (2011, p. 225) analisa o papel da intervenção das fundações privadas nos EUA e afirma que "elas assumiram por si mesmas a tarefa de reformar a educação pública, talvez de maneiras que nunca sobreviveriam ao escrutínio dos eleitores em qualquer distrito ou estado. Se os eleitores não gostam da política de reforma da fundação, eles não podem votar para que ela saia do cargo".

No quadro a seguir, são apresentados alguns dos doadores do Instituto Brookings, devidamente alocados na sua faixa de doação.

Tabela 3 - Doadores Instituto Brookings

\begin{tabular}{|c|c|c|}
\hline Faixa de doação em U\$ & Nome da Instituição & Total de Doadores \\
\hline 2.000 .000 ou mais & $\begin{array}{l}\text { Bill \& Melinda Gates Foundation } \\
\text { Anne T. and Robert M. Bass }\end{array}$ & 06 \\
\hline $1.000 .000-1.999 .999$ & $\begin{array}{l}\text { Laura and John Arnold Foundation } \\
\text { BHP Foundation }\end{array}$ & 10 \\
\hline $500.000-999.999$ & $\begin{array}{l}\text { Ford Foundation } \\
\text { LEGO Foundation }\end{array}$ & 16 \\
\hline $250.000-499.999$ & $\begin{array}{l}\text { Bank of America } \\
\text { Microsoft Corporation } \\
\text { The Rockefeller Foundation }\end{array}$ & 38 \\
\hline $100.000-249.999$ & $\begin{array}{l}\text { Shell } \\
\text { Facebook } \\
\text { Hewlett-Packard Company } \\
\text { Omidyar Network } \\
\text { PepsiCo } \\
\text { Volvo Research and Educational Foundation }\end{array}$ & 92 \\
\hline $50.000-99.999$ & $\begin{array}{l}\text { Amazon.com } \\
\text { Intel Corporation } \\
\text { Visa Inc. }\end{array}$ & 88 \\
\hline $25.000-49.999$ & Airlines for America & 67 \\
\hline $10.000-24.999^{*}$ & & 94 \\
\hline $5.000-9.999^{*}$ & & 40 \\
\hline Up to $4.999^{*}$ & & 176 \\
\hline Total & & 527 \\
\hline
\end{tabular}

Fonte: Brookings 2018, Annual Report

* nessas faixas não são mencionados os nomes, apenas a quantidade de doadores. 
Na Tabela 3, aparecem empresas que operam no ramo financeiro, automobilístico, aéreo, de combustíveis, de brinquedos, de bebidas, de e-comerce. Empresas com atuação diversificada no mercado e que estão presentes em diferentes partes do planeta, tanto no comércio quanto na produção de mercadorias. Foram 527 doadores no ano de 2018 para o Instituto Brookings. São volumosos aportes financeiros feitos diretamente por empresas, ou fundações vinculadas a empresas ou a grandes acionistas, para financiar think tanks que levam as forças pró-mercado e os valores capitalistas para diversos campos da vida social.

Neste estudo, interessa compreender como se constitui e como atua o Instituto Brookings, tanto pelo lugar que ocupa como um think tank no mundo, quanto pela parceria que firma com uma importante organização brasileira que realiza amplo trabalho na área educacional, a Fundação Getúlio Vargas (FGV). No relatório da Universidade da Pensilvânia, a FGV aparece em primeiro lugar, como o think tank mais influente na América do Sul e Central.

No ano de 2016 é inaugurado no Brasil o Ceipe, lotado na Escola de Administração Pública e de Empresas (Ebape) da FGV. O Ceipe está vinculado ao Programa de Política Educacional Internacional da Universidade de Harvard e conta com o apoio do Instituto Brookings. No Brasil seus parceiros são: a Fundação Lemann, o Instituto Unibanco, o Instituto Natura, o Itaú Social, a Fundação Maria Cecília Souto Vidigal, o Itaú BBA e a Omidyar Network. Compõem o conselho da organização representantes da Fundação Lemann, da Fundação Maria Cecília Vidigal, do Instituto Unibanco, da Aondê Educacional, da Granergia, do Todos pela Educação e representantes da FGV.

De acordo com os dados disponibilizados pela FGV, trata-se do primeiro think tank brasileiro especializado em política educacional que pretende influenciar a organização das políticas nas secretarias de educação no país.

O Ceipe tem como missão contribuir para que o Brasil tenha uma educação pública equitativa, inovadora e de qualidade por meio do apoio às Secretarias no desenho e implementação de políticas educacionais, da produção de conhecimento aplicado em políticas educacionais e da formação de líderes (FUNDAÇÃO GETÚLIO VARGAS, 2019).

Com o declarado propósito de melhorar a educação brasileira, o Ceipe concentra suas atividades em três áreas de trabalho: apoio às redes públicas de ensino, produção de conhecimento aplicado e formação de líderes. Como já mencionado, está lotado na Ebape, uma unidade da FGV, que, tradicionalmente, forma administradores de empresas em uma perspectiva afinada com a lógica do mercado. Conceitos como meritocracia, concorrência, liderança e liberdade individual orien- 
tam o trabalho dessa organização e da formação acadêmica dos estudantes que frequentam cursos de graduação e pós-graduação na instituição.

O Ceipe apresenta-se como um think tank que pretende contribuir diretamente na qualificação da educação básica ao afirmar: "possuímos uma visão ambiciosa: almejamos nos tornar um centro de referência nacional e internacional em políticas educacionais, contribuindo de forma significativa e duradoura para a melhoria da educação básica brasileira" (FUNDAÇÃO GETÚLIO VARGAS, 2019, não paginado). Mesmo com o curto período de existência o Ceipe já atuou em quatros municípios brasileiros: Pelotas/RS, Lajeado/RS, Guarulhos/SP e Taubaté/SP. Entre as ações desenvolvidas estão: gestão pedagógica, gestão da rede e gestão financeira.

Esse braço da FGV tem menos de três anos de existência, mas merecerá um acompanhamento da comunidade acadêmica, pois sustenta suas propostas e projetos na lógica do mercado e pretende exercer grande influência na organização das políticas educacionais. Para as organizações que pautam sua atuação na defesa incondicional à propriedade privada e à economia de mercado, o monopólio do Estado na definição e indução dos modelos educacionais para uma nação, representa uma ameaça à perpetuação de valores e princípios que promovam a conservação das estruturas sociais.

A seguir, abordaremos o Instituto Millenium, que se define como um think tank representativo dos interesses das classes dominantes brasileiras (CASIMIRO, 2018a), com estrutura e meios organizacionais que pretendem a penetração em instâncias de decisão estatais e, a área educacional, é uma delas.

\section{Instituto Millenium: o liberalismo e o mercado na educação}

O Instituto Millenium foi lançado em 2006, durante a realização do XIX Fórum da Liberdade, em Porto Alegre/RS. De acordo com Casimiro (2018b), o discurso em defesa do mercado e dos princípios liberais atraiu membros que atuavam em meios de comunicação de largo alcance no país, como TV Globo; Grupo Abril; Jornais Folha de São Paulo, O Estado de S. Paulo e Valor Econômico. Para Casimiro (2018b, p. 44) "uma fração representativa desses jornalistas e empresários está ligada a inúmeras universidades brasileiras e, de alguma forma - seja como colunista, redator ou como dirigente -, a outros importantes veículos de comunicação da grande mídia brasileira", o que significa o alcance de milhões de pessoas, de diferentes grupos e camadas sociais, com grande capilaridade no tecido social brasileiro. 
Uma publicação no site do Instituto Millenium do ano de 2009, intitulada "O que significa um think tank no Brasil hoje" permite a compreensão de qual é a concepção dessa organização.

O conceito de think tank faz referência a uma instituição dedicada a produzir e difundir conhecimentos e estratégias sobre assuntos vitais - sejam eles políticos, econômicos ou científicos. Assuntos sobre os quais, nas suas instâncias habituais de elaboração (estados, associações de classe, empresas ou universidades), os cidadãos não encontram facilmente insumos para pensar a realidade de forma inovadora (INSTITUTO MILLENIUM, 2009).

Na perspectiva do Instituto Millenium os think tanks são capazes de fornecer respostas aos problemas coletivos de forma mais eficiente que os governos. Há uma reivindicação da condução e da formulação das políticas por parte dessas organizações. Isso representa uma brutal ameaça à democracia na medida em que essa condução é repassada para instâncias privadas sem a legítima delegação do voto.

No referido artigo é afirmado, se "comparado com a realidade dos Estados Unidos e dos principais países europeus, o Brasil é hoje quase um deserto de think tanks". De fato, de acordo com a Tabela 2, apresentada anteriormente, no ano de 2008 o Brasil, figurava na $24^{a}$ colocação, com 39 think tanks no Relatório da Pensilvânia, número pequeno se comparado aos países que ocupavam as primeiras colocações.

O Instituto Millenium propõe-se a atuar como um verdadeiro intelectual coletivo (CASIMIRO, 2018a) voltado para a difusão da ideologia ${ }^{2}$ do mercado, sustentado na crítica ao intervencionismo do Estado como responsável pela criação de obstáculos ao crescimento econômico do país. Essa percepção pode ser identificada no seguinte trecho da publicação da organização, "nas sociedades modernas e cada vez mais complexas, [...], há a necessidade de espaços que reúnam pessoas de destaque, com autonomia suficiente para se atreverem a contestar criativamente as tendências dominantes, especialmente quando elas se tornam anacrônicas" (INSTITUTO MILLENIUM, 2009).

Para alavancar ideias e propor soluções para os problemas brasileiros, a negação da ideologia e a defesa da neutralidade do pensamento são declarados como princípios que devem orientar o comportamento daqueles que integram um think tank pró mercado:

[...] um think tank está obrigado a colocar as ideologias num segundo plano. Seus membros não podem nunca guiar seus comportamentos de forma ideológica, se quiserem cumprir seu papel. As ideologias podem dar eventualmente subsídios importantes para pensar a realidade, mas na hora de emitir juízos e elaborar estratégias, antes de qualquer ideologia, se coloca a análise crua e concreta da dinâmica da realidade. Por assim dizer, os think tanks devem, assumir seus valores de forma científica e pragmática (INSTITUTO MILLENIUM, 2009). 
Para assegurar credibilidade e confiabilidade a um think tank pró-mercado é defendida a sua competência técnica, desprovida de intencionalidade política. Esse discurso se mantem mesmo quando integrantes da organização vão ocupar cargos importantes em uma gestão governamental. A CEO do Instituto Millenium, Priscila Pereira Pinto, quando questionada sobre a escolha de nomes como Paulo Guedes, Salim Mattar, Marcos Troyjo e Paulo Uebel, ligados ao instituto, para compor a equipe do governo Jair Bolsonaro declarou:

A gente está sentindo um orgulho enorme. O Instituto Millenium contribui há mais de dez anos com conteúdo para um público bem amplo. Ao longo desses dez anos, essas pessoas fizeram parte da nossa rede de articulistas, rede de entrevistados, rede de conselheiros. Foi muito empolgante para o instituto ver que esse conteúdo, isto é, as ideias que eles compartilhavam no nosso site, nas nossas redes sociais, nos nossos eventos e no "Imil na sala de aula", chegaram ao governo. Por essas pessoas serem muito técnicas e preparadas acabam sendo convidadas a executar propostas específicas com todo esse conhecimento que têm (PINTO, 2018).

É relevante destacar que mesmo ocupando funções importantes em um governo, com declarada e evidente afinidade com viés político conservador, a CEO insiste no pressuposto da competência técnica, como requisito eminentemente necessário para a execução e indicação para as funções.

Em uma busca no site, para compreender a composição orçamentária do Instituto Millenium, localizamos um quadro com receitas e despesas de 2009 a 2018 e relatórios de atividades de exercícios de 2015 a 2018. São documentos resumidos, mas permitem identificar que as receitas duplicam de 2009 para 2018 e que são predominantemente formadas por doações.

Tabela 4 - Evolução das despesas e receitas do Instituto Millenium

\begin{tabular}{l|r|r}
\hline \multicolumn{1}{c|}{ Natureza da Receita } & $\mathbf{2 0 0 9}$ & \multicolumn{1}{|c}{$\mathbf{2 0 1 8}$} \\
\hline Doações & $524.000,00$ & $952.083,76$ \\
Financeiras & $54.000,00$ & $305.947,18$ \\
Eventos & $42.000,00$ & $6.000,00$ \\
DESPESAS & $\mathbf{6 3 2 . 0 0 0 , 0 0}$ & $\mathbf{1 . 0 4 1 . 5 6 5 , 1 3}$ \\
Operacionais & $393.500,00$ & $845.563,25$ \\
Website & $37.500,00$ & $135.822,38$ \\
Eventos e ações & $154.000,00$ & $23.136,64$ \\
Redes & $34.500,00$ & $33.871,02$ \\
Financeiras e outras & $12.800,00$ & $3.171,84$ \\
SALDO & $12.000,00$ & $222.465,81$ \\
FUNDO PATRIMONIAL & $160.000,00$ & $316.884,63$ \\
\hline TOTAL DE RECEITAS & $620.000,00$ & $\mathbf{1 . 2 6 4 . 0 3 0 , 9 4}$ \\
\hline
\end{tabular}

Fonte: INSITUTO MILLENIUM. 
O predomínio das despesas está na faixa "operacional”, no entanto, não é onde se evidencia a maior concentração de gastos, já que nos relatórios de exercício os eventos são as atividades que prevalecem no Instituto Millenium. Os referidos relatórios de exercício, disponíveis para consulta, limitam-se à exposição dos eventos promovidos e/ou apoiados pela organização, com dados como: nome do evento, data, público presencial, palestrante e tema. Não há um detalhamento de onde vêm os recursos, quem são os doadores ou apoiadores.

Interessa particularmente a este estudo destacar o "IMIL na sala de aula" que são atividades realizadas no interior de instituições de ensino superior no país, com o objetivo de "discutir com os jovens valores como liberdade, Estado de direito, economia de mercado e democracia” (INSTITUTO MILLENIUM, 2018). São atividades promovidas gratuitamente pelo Instituto Millenium para possibilitar o encontro entre "especialistas de sua rede e alunos dos cursos de graduação". A especificidade de um think tank de difundir valores e formar a opinião pública - contrariando a pretensa neutralidade - se explicita nesta declaração: "O Instituto Millenium acredita que é de fundamental importância difundir seus valores entre o público jovem, pelo seu importante papel na construção de um Brasil mais próspero e jovem" (INSTITUTO MILLENIUM, 2018). A CEO da organização, faz algumas considerações ao avaliar essa ação do Instituto.

O Imil na sala de aula é o meu "bebê". É um projeto que eu criei em 2011 para o Instituto Millenium. Antes de virar CEO do Instituto, dava palestras para universidades, lidava diretamente com jovens, e percebia que faltava conteúdo em sala de aula, até nas apresentações dos professores, para que pudessem debater qualquer assunto. Por exemplo, direitos humanos, microeconomia. Havia um déficit de conteúdo tanto material quanto oral. Os professores só tinham uma visão estabelecida. Entravam em sala de aula, só passavam essa visão e os alunos compravam a ideia, mas no fundo ficavam em dúvida se só tinha isso mesmo funcionando no Brasil. Como tínhamos uma rede de 120 especialistas no Instituto Millenium, nos perguntamos sobre e por que não convidar essas pessoas para palestrar nas salas de aula. Muitos não são professores, sequer palestrantes, mas são especialistas, técnicos na área em que atuam. Essas pessoas podiam entrar em sala de aula e conversar, por exemplo, sobre o que é o tripé econômico, o que é a liberdade de expressão, o que são as fake news. $\mathrm{O}$ alvo inicial eram as universidades públicas, tanto federais quanto estaduais. Mas o projeto ficou de tal tamanho que até os particulares começaram a convidar o Instituto Millenium a entrar. $O$ nosso relacionamento é diretamente com os alunos: a gente não passa pela burocracia da reitoria, de conversas com mil departamentos entre universidades. Não é essa a proposta (PINTO, 2018, grifo nosso).

Esse é um dado que merece reflexão, pois nas instituições públicas de ensino superior os eventos são, normalmente, discutidos, analisados e avaliados em várias instâncias, justamente para assegurar tanto o conhecimento e o registro, quanto 
a pertinência da ação no interior da instituição. São registros públicos que podem ser acessados por qualquer cidadão de forma transparente. Não se trata de mera burocracia, mas de uma forma de organização do trabalho que possibilite o controle social sobre a coisa pública e impeça que cada indivíduo tome suas decisões e faça suas escolhas, como o faz no âmbito privado da sua existência. Ao buscar atuar diretamente com os alunos e fazer uma crítica à organização das universidades, o Instituto Millenium procura, na realidade, introduzir outra forma de agir em uma organização pública, mais individualista e privada e menos transparente e democrática.

O "IMIL na sala de aula" já realizou 135 edições, em instituições públicas ${ }^{3}$ e privadas, que ocorreram nas regiões sul, sudeste, nordeste e centro oeste do país. Há um pequeno predomínio dessa promoção nas instituições privadas, que receberam pouco mais da metade dos palestrantes do Instituto Millenium, com destaque para as católicas, como Pontifícia Universidade Católica do Rio Grande do Sul e Universidade Católica de Brasília, que tiveram sete e cinco eventos, respectivamente. Entre as públicas a Universidade de São Paulo, a Universidade Federal do Mato Grosso do Sul e a Universidade Federal do Rio de Janeiro concentraram os maiores números de atividades com nove, oito e sete palestras, respectivamente.

Os temas das palestras são bastante variados e versam sobre macroeconomia, capitalismo de Estado, liberalismo, empreendedorismo, criatividade, inovação, meritocracia. Com relação aos palestrantes observamos que prevalece uma diversidade de expositores. Contabilizaram-se nas 135 edições 68 palestrantes diferentes para conduzir as atividades, sendo destes apenas nove mulheres. Em sua maioria, são realizadas individualmente, já que, em apenas oito edições, atuaram duplas ou trios de palestrantes. Merece destaque a atuação de Vitor Wilher, com a participação em 18 momentos diferentes, expondo sobre temas variados como: economia de mercado; criatividade, inovação e desenvolvimento econômico; meritocracia e cobrança de mensalidades nas universidades.

Na edição 128, do "IMIL na sala de aula", realizada na Universidade Federal de Pelotas, no ano de 2019, com o tema "Cobrança de mensalidades nas universidades”, o palestrante Vitor Wilher, logo no início da sua exposição, afirmou que aquela palestra encontraria muitas barreiras em uma instituição pública alguns anos antes. Isto porque, na sua opinião, certamente grupos identificados com partidos de esquerda promoveriam manifestações para impedir a realização de um evento, que pretendesse discutir a cobrança de mensalidades, em uma universidade pública, mas reconhece, com evidente satisfação, que se trata de um outro momento em que 
- ao se falar sobre um tema como esse, que ataca um dos pilares mais importantes da educação pública brasileira, dentro de uma instituição federal de ensino - não se encontra resistência, impedimento ou mesmo manifestação contrária.

Barreiras antes intransponíveis agora são atravessadas. Cumpre o seu papel o think tank de "difundir seus valores entre o público jovem pelo seu importante papel na construção de um Brasil mais próspero e livre” (INSTITUTO MILLENIUM, 2018).

[...] a questão crucial, sob o domínio do capital, é assegurar que cada indivíduo adote como suas próprias as metas de reprodução objetivamente possíveis do sistema [...] no sentido verdadeiramente amplo do termo educação, trata-se de uma questão de "internalização" pelos indivíduos [...] da legitimidade da posição que lhes foi atribuída na hierarquia social, juntamente com suas expectativas 'adequadas' e as formas de conduta 'certas', mais ou menos explicitamente estipuladas nesse terreno. (MÉSZAROS, 2005, p. 44, grifos do autor).

$\mathrm{Na}$ análise de cada edição do "IMIL na sala de aula" percebemos que a quantidade de presentes varia de instituição para instituição. Há eventos com 650 participantes em uma edição e eventos com 7 em outra. De modo geral, há um predomínio de palestras com menos de 60 pessoas. Porém, ainda que o número de presentes possa ser um indicador importante para avaliar a amplitude do público atingido e, consequentemente, pela possibilidade de exposição de determinados valores e conhecimentos, o que talvez mereça uma atenção maior é a receptividade que determinados temas passam a ter nas instituições de ensino, o que minimiza a relevância do número de participantes e amplia a importância da penetração e de um possível enraizamento de determinados valores e princípios no interior das instituições de ensino, como ocorreu na Universidade Federal de Pelotas.

A produção e a disseminação de material é uma das estratégias utilizadas pelos think tanks para convencer as pessoas sobre suas formas de enxergar o mundo, suas convicções e suas propostas de intervenção na realidade, ainda que insistam na premissa de que são neutros, desprovidos de ideologia, apartidários ${ }^{4}$. Entre os materiais disponíveis para consulta no site do Instituto Millenium foram aqui selecionados aqueles que representam mais fortemente a força que o capital exerce na formação humana, justamente pelo tipo de público que almeja atingir. Além do "Imil na sala de aula" foi, para este estudo, analisada a produção e divulgação de dois livros infantis. O link em destaque dentro do site do Instituto Millenium chamado "Turminha da Liberdade" remete para a divulgação de dois livros produzidos pelo Instituto Liberdade e Justiça (ILJ), seguido de ampla matéria, produzida pelo Instituto Millenium, sobre as características e o conteúdo dos livros: "Antônio e o 
segredo do universo em breves lições" e "Anya e o mistério do sumiço do cãozinho Galt” (INSTITUTO MILLENIUM, 2019).

Os dois livros são inspirados nas ideias defendidas por nomes do liberalismo como Ludwig Von Misses. O livro “Antônio e o segredo do universo em breve lições”, pretende "trazer para o universo infantil os ensinamentos contidos no livro "As seis lições', do economista Ludwig von Mises” (INSTITUTO MILLENIUM, 2019). O autor do livro, Giuliano Miotto, afirma na matéria que deseja "levar o liberalismo aos pequenos" (INSTITUTO MILLENIUM, 2019), e destaca a importância de trabalhar valores, desde os primeiros anos de vida escolar e não escolar das crianças, que favoreçam a conservação das estruturas do capital. Em uma declaração ${ }^{5}$ o autor do livro afirma:

Acredito na importância dos valores que a Turminha defende. O que está sendo passado para as crianças são valores errados e coletivistas e que retiram a importância e a responsabilidade do indivíduo. A meritocracia, por exemplo, é mal-entendida. Muitos acham que o mérito dos outros tem que ser dividido com todos. Portanto, ensinar meritocracia, no ambiente escolar, é fundamental, já que a escola vem privilegiando a mediocridade", critica Miotto, salientando a ineficiência do sistema também com os professores: É um sistema todo errado que premia mal os bons profissionais. Os bons professores da rede pública não têm estímulo nenhum para serem bons ou investirem o tempo deles em conhecimento e em uma boa didática. A meritocracia é fundamental para que o sistema educacional brasileiro saia deste buraco onde ele está. A educação precisa de liberdade, inclusive didática. Ter mais liberdade de conteúdos e não ficar tão amarrada a uma agenda governamental, que é também um fator que prejudica bastante a educação infantil (INSTITUTO MILLENIUM, 2019).

Essa produção para o público infantil é reveladora do propósito de internalizar $^{6}$ nas crianças os princípios e valores que orientam o capital, o que comprova a existência de uma verdadeira batalha de ideias em disputa por um projeto de educação para o país.

Nas duas ações do Instituto Millenium aqui analisadas evidenciamos uma crítica ao trabalho dos professores, no primeiro ("Imil na sala de aula"), por apresentarem uma única visão aos alunos sobre determinados temas; na segunda (livros infantis), por não estarem sujeitos a um sistema de bonificação e compensação pelo esforço individual e pelo mérito, não teriam qualidade.

\section{Considerações finais}

Já foi amplamente demostrado pela literatura educacional brasileira (SAVIANI, 2018; PARO, 2012; PERONI 2016) a incompatibilidade entre os valores que orientam a ação do mercado e os que sustentam um projeto de educação democráti- 
ca. Se, no primeiro, a exploração da força de trabalho, as relações de mando e submissão, a valorização da concorrência, a criação de rankings e o estabelecimento de classificações são inerentes a um sistema que tem como finalidade o aumento da taxa de lucro e da riqueza; no segundo, tais premissas se constituem verdadeiros entraves à formação de sujeitos independentes. Neste caso, à escola cabe contribuir para criar as condições para uma percepção do lugar que cada um ocupa na sociedade e sua relação com as condições históricas que produziram as diferenciações de posições. Um projeto de educação democrática busca uma formação que possibilite uma intervenção qualificada na vida social na luta por uma sociedade mais justa e menos desigual.

Os think tanks pró-mercado, na condição de "laboratório de ideias", têm cumprido o papel de desconstruir e destruir qualquer projeto que se volte para a coletividade. A eliminação das hierarquias nas instituições de ensino, a formação de coletivos, o compartilhamento de decisões, o abandono do princípio da avaliação escolar classificatória, tão reivindicados pela sociedade brasileira (movimentos sociais, sindicatos, organizações estudantis) nas últimas décadas, sofre um processo de destruição interna. A valorização da colaboração dá lugar à competição, à responsabilização e ao individualismo. Os princípios adotados no mercado para obter lucro, precisam agora fazer parte do universo educacional.

No caso brasileiro, olhamos neste estudo, para duas organizações que aparecem no Relatório da Pensilvânia como instituições que exercem influência interna no país, para identificar algumas premissas que orientam suas ações no campo educacional. Foram escolhidos o Instituto Millenium e a Fundação Getúlio Vargas. O primeiro, pela vinculação com as questões econômicas e por ter integrantes em seus quadros que exercem funções nos governos. Esse perfil é relevante porque as determinações das políticas econômicas repercutem em todas as áreas de atuação do governo. Olhar para as políticas globais é necessário para entender como se constituem as ações na área educacional. O segundo, pela sólida atuação no país e, especialmente, por ter criado recentemente um segmento definido como o primeiro think tank brasileiro de política educacional.

Observamos, ainda, as implicações para a democratização da educação, em nosso país e as consequências para um projeto societário democrático, pela importância que tem a educação para essa construção. A existência de think tanks espalhados pelo mundo com viés progressista, não atrelados aos interesses do capital, não tem sido capaz de fazer frente à pesada influência de organizações que são financiadas por grandes empresas com capacidade de penetração na imprensa, nos 
governos, nas universidades, nas mídias sociais, na indústria cultural. São gerações formadas em um modelo pautado na aceitação dos princípios que reproduzem os valores dominantes na sociedade e na resignação em relação à posição social ocupada por cada indivíduo (MÉSZAROS, 2005).

\section{Notas}

1 Grupo das 19 maiores economias do mundo mais a união europeia.

2 Conceito refutado pela organização que se posiciona contra as ideologias.

${ }_{3} \mathrm{Na}$ análise das edições do IMIL na sala de aula foram contabilizadas atividades em 22 instituições de ensino superior públicas diferentes (a maioria é federal) e em 34 privadas. Há um número inexpressivo de palestras que foram realizadas em empresas, secretarias de algum estado ou em um evento. O último levantamento foi realizado em 30 de julho de 2019.

4 "Apartidária, a organização já lançou livros, eventos, vídeos e podcasts" (Boletim da Liberdade, 2018).

5 O Instituto Millenium realiza uma entrevista com o autor do livro, Giuliano Miotto, para produzir a referida matéria de divulgação do material.

6 Expressão utilizada por Mészaros (2005) para tratar de valores e conceitos que são aceitos pelos indivíduos, a partir de longos processos de legitimação, dos quais as instituições educacionais fazem parte, de expansão do modo de produção capitalista.

\section{Referências}

BROOKINGS INSTITUTE. 2018. Annual Report. Disponível em: https://www.brookings.edu/ wp-content/uploads/2018/11/2018-annual-report.pdf. Acesso em: 15 mar. 2019.

CASIMIRO, Flávio Henrique Calheiros. A nova direita no Brasil: aparelhos de ação política e ideológica no Brasil contemporâneo. São Paulo: Expressão Popular, 2018a.

CASIMIRO, Flávio Henrique Calheiros. As classes dominantes e a nova direita no Brasil contemporâneo. In GALLEGO, Esther. O ódio como política: a reinvenção das direitas no Brasil. São Paulo: Boitempo, 2018b.

CLARKE, Jonh, NEWMAN, Janet. Gerencialismo. Educação e Realidade, Porto Alegre, v. 37, n. 2, p. 353-381, maio/ago. 2012.

FUNDAÇÃO GETÙLIO VARGAS. Centro de Excelência e Inovação em Políticas Educacionais. Disponível em: https://ceipe.fgv.br/. Acesso em: 15 jun. 2019.

GAMBOA, Silvio Sánchez. Pesquisa em educação: métodos e epistemologias. Chapecó: Argos, 2012.

GIDDENS, Antony. A terceira via: reflexões sobre o impasse político atual e o futuro da social-democracia. Rio de Janeiro: Record, 2001a.

GIDDENS, Antony. A terceira via e seus críticos. Rio de Janeiro: Record, 2001b.

GIDDENS, Antony (Org.). O debate global sobre a terceira via. São Paulo: Editora Unesp, 2007.

HARVEY, David. Neoliberalismo: história e implicações. Edições Loyola. 2008. 
INSTITUTO MILLENIUM. Imil na sala de aula. Disponível em: https://www.institutomillenium.org.br/imil-na-sala-de-aula/. Acesso em: 30 nov. 2018.

INSTITUTO MILLENIUM. O que significa um think tank no Brasil hoje. 2009. Disponível em: https://www.institutomillenium.org.br/artigos/o-que-significa-um-think-tank-no-brasil-de-hoje/. Acesso em: 24 nov. 2018.

INSTITUTO MILLENIUM. Turminha da liberdade lança segundo livro: "Antônio e o segredo do universo em sete lições” leva valores liberais para as crianças. Disponível em: https://www. institutomillenium.org.br/factiva/turminha-da-liberdade-lanca-segundo-livro/. Acesso em: 15 jul. 2019.

MÉSZAROS, István. A educação para além do capital. São Paulo: Boitempo, 2005.

MÉSZÁROS, István. Para além do capital. São Paulo: Boitempo; Campinas: Editora da UNICAMP, 2002.

MOLL NETO NETO, Roberto. Reaganation: a nação e o nacionalismo (neo) conservador nos Estados Unidos (1981-1988). Dissertação (Mestrado em História) - Programa de Pós-Graduação em História, Universidade Federal Fluminense, 2010.

MORAES. Reginaldo C. A organização das células neoconservadoras de agitprop: o fator subjetivo da contrarrevolução. In: CRUZ, Sebastião, KAYSEL, André, CODAS Gustavo (Org). Direita Volver! O retorno da direita e o ciclo econômico brasileiro. São Paulo: Fundação Perseu Abramo, 2015.

PARO, Vitor Henrique. Administração escolar: introdução crítica. São Paulo: Cortez, 2012.

PERONI, Vera Maria Vidal, CAETANO, Maria Raquel, LIMA Paula Valim. Reformas educacionais de hoje: as implicações para a democracia. Retratos da Escola, v. 11, n. 21, p. 415-432, jul/ dez 2017. Disponível em: http://retratosdaescola.emnuvens.com.br/rde/article/view/793. Acesso em: 12 jun. 2019.

PERONI, Vera. Implicações da relação público-privada para a democratização da educação no Brasil. 2016. 264 f. Tese (promoção a Professor Titular da Carreira do Magistério Superior), Faculdade de Educação, Universidade Federal do Rio Grande do Sul, Porto Alegre, 2016.

PERONI, Vera. As Relações entre o Público e o Privado nas Políticas Educacionais no Contexto da Terceira Via. Currículo sem Fronteiras: Privatização da educação no contexto da(s) “Terceira(s) Via(s)”: uma caracterização em análise. v. 13, n. 2, maio/agosto. 2013. Disponível em: http://www.curriculosemfronteiras.org/vol13iss2articles/peroni.htm. Acesso em: 20 out. 2018.

PINTO, Priscila Pereira. Entrevista. Boletim da Liberdade, online, 27 dez. 2018. Disponível em: https://www.boletimdaliberdade.com.br/2018/12/27/a-gente-ajudou-na-mudanca-de-mentalidade-do-brasileiro-diz-ceo-do-instituto-millenium-ao-boletim/. Acesso em: 30 mai. 2019.

RIKOWSKI, Glenn. Privatização em educação e formas de mercadoria, Revista Retratos da Escola, Brasília, v. 11, n. 21, p. 393-413, jul./dez. 2017.

ROCHA, Camila. Direitas em rede: think tanks de direita na América Latina. In: CRUZ, Sebastião Velasco; KAYSEL, André; CODAS Gustavo (Org.). Direita, volver! O retorno da direita e o ciclo polıtico brasileiro. São Paulo: Fundação Perseu Abramo, 2015.p. 261-278. 
ROCHA, Camila. O papel dos think tanks pró-mercado na difusão do neoliberalismo no Brasil. RAVITCH, Diane. Vida e morte do grande sistema escolar norte americano: como os testes padronizados e o modelo de mercado ameaçam à educação. Porto Alegre: Sulina, 2011.

MILLCAYAC -Revista Digital de Ciencias Sociales. Centro de Publicaciones. FCPyS. UNCuyo. Mendoza. Vol. 4, n.7, 2017, p. 95-120.

SAVIANI, Demerval. Escola e democracia. 39. ed. Campinas: Autores Associados, 2018.

TEIXEIRA, Tatiana. Os think tanks e sua influência a politica externa dos EUA. Rio de Janeiro, Revan, 2007.

THOMPSON. E. P. A miséria da teoria ou um planetário de erros uma crítica ao pensamento de Althusser. Rio de Janeiro: Zahar Editores, 1981.

THOMPSON, E. P. As peculiaridades dos ingleses e outros artigos. Campinas: Editora UNICAMP, 2012.

UNIVERSITY OF PENSYLVANIA. 2009, Global Go To Think Tank Index Report. 2010. Disponível em: https://repository.upenn.edu/cgi/viewcontent.cgi?article=1017\&context=think_tanks. Acesso em 23 de fev. 2019

UNIVERSITY OF PENSYLVANIA. 2017, Global Go To Think Tank Index Report. 2018. Disponível em: https://repository.upenn.edu/cgi/viewcontent.cgi?article=1017\&context=think_tanks. Acesso em 23 de fev. 2019

UNIVERSITY OF PENSYLVANIA. 2018, Global Go To Think Tank Index Report. 2019. Disponível em: https://repository.upenn.edu/cgi/viewcontent.cgi?article=1017\&context=think_tanks. Acesso em 23 de fev. 2019

VIEIRA, Evaldo. A social-democracia, longo caminho até a Terceira Via. In Currículo sem Fronteiras: Privatização da educação no contexto da(s) "Terceira(s) Via(s)": uma caracterização em análise. v. 13, n. 2, maio/agosto. 2013. Disponível em: http:/www.curriculosemfronteiras.org/ vol13iss2articles/vieira.htm. Acesso em: 25 mai.2019. 